\title{
Chemoradiotherapy and concurrent radiofrequency thermal therapy to treat primary rectal cancer and prediction of treatment responses
}

\author{
HISANORI SHOJI $^{1}$, MASAHIKO MOTEGI ${ }^{1}$, YOSUKE TAKAKUSAGI ${ }^{2}$, TAKAYUKI ASAO ${ }^{3}$, \\ HIROYUKI KUWANO $^{4}$, TAKEO TAKAHASHI ${ }^{5}$ and KYOJI OGOSHI ${ }^{6}$
}

\author{
${ }^{1}$ Division of Surgery and ${ }^{2}$ Oncology Center, Hidaka Hospital, Gunma 370-0001; ${ }^{3}$ Initiative for Advanced Research, \\ Gunma University, Gunma 371-8511; ${ }^{4}$ Department of General Surgical Science, Graduate School of Medicine, \\ Gunma University, Gunma 371-8511; ${ }^{5}$ Department of Radiation Oncology, Saitama Medical Center, \\ Saitama Medical University, Saitama 350-8550; ${ }^{6}$ Division of Cancer Diagnosis \\ and Cancer Treatment, Hidaka Hospital, Gunma 370-0001, Japan
}

Received May 24, 2016; Accepted August 10, 2016

DOI: $10.3892 /$ or.2016.5300

\begin{abstract}
The present study aimed to evaluate a previously reported predictive formula of output-limiting symptoms induced by radiofrequency (RF) to determine the efficacy of this neoadjuvant chemoradiation (NACR) and concurrent RF thermal therapy. The present study included 81 consecutive patients with confirmed diagnoses of rectal adenocarcinoma that was localized in the mid-low rectum (up to $12 \mathrm{~cm}$ from the anal verge) who received NACR [intensity-modulated radiotherapy (IMRT), $50 \mathrm{~Gy} / 25$ fractions, capecitabine $1,700 \mathrm{mg} / \mathrm{m}^{2} /$ day for 5 days/week)] with concurrent thermal therapy (Thermotron-RF8, once a week for 5 weeks with $50 \mathrm{~min}$ irradiation). Patients with progressive disease (PD) did not receive RF outputs higher than the predicted value. Some patients who were predicted to receive more output in fact received more than the predicted output. In patients who were predicted to receive moderately higher outputs, $37.5 \%$ of the patients experienced pathological complete responses, which was the highest rate, while in those who did not receive more than the predicted output, $66.7 \%$ of the patients experienced $\mathrm{PD}$, which was the highest rate in the present study. We speculate that RF thermal therapy may offset the chemoradiation effects in some patients. Adding thermal therapy as a multimodality therapy to NACR potentially affects patients with lower predicted outputs and actual observed outputs slightly higher than the predictive value. Our predictive equation for initial energy output, in which output-limiting symptoms can
\end{abstract}

Correspondence to: Dr Hisanori Shoji, Division of Surgery, Hidaka Hospital, 886 Nakao-machi, Takasaki-shi, Gunma 370-0001, Japan

E-mail: h_shoji@hidaka-kai.com

Key words: radiofrequency thermal therapy, chemoradiotherapy, rectal cancer, standardized power escalation principles, output-limiting symptoms be used to predict treatment efficacy, consequently, can be used to decide whether to continue this treatment modality.

\section{Introduction}

Since the National Comprehensive Cancer Network Practice Guidelines for treatment of primary rectal cancer were specified in 2009, neoadjuvant chemoradiation (NACR) has been accepted as the standard therapy worldwide, except in Japan. Numerous studies have shown that NACR increases local control of the tumor, but no effect on overall patient survival has been reported (1-6).

Conversely, recent studies have shown the benefits of NACR, including good pathological responses to therapy and increased rates of disease-specific and overall survival (7-15).

However, pathologic complete response (pCR) rates are reported to be only $10-29.3 \%$, and more than one-third of patients do not respond to treatment. New strategies to achieve complete responses using multimodality neoadjuvant therapy are required for rectal cancer. Therefore, the present study aimed to establish new strategies that may increase the pCR rate for patients treated with NACR with concurrent thermal therapy.

Radiofrequency (RF) hyperthermia using the Thermotron-RF8 has been performed mainly in Japan; however, it has two major issues: i) this modality has not been approved as a standardized treatment in oncology since each hyperthermic treatment is not of the same quality; and ii) there are risks for fatal hot spot or thermal runaway phenomena, which are induced by the RF treatment itself $(16,17)$.

As for the latter, we previously reported that a good predictive equation for initial energy output at which output-limiting symptoms occur was determined with two parameters: initial time of output-limiting symptom onset and abdominal wall fat thickness, using standardized power escalation principles (18). This formula had an adjusted $\mathrm{R}^{2}$ of 0.99 , and all variance inflation factor (VIF) values were $<2$. The initial energy output [initial RF output (IRO)] at which an output-limiting symptom 
occurred $($ Watt $)=$ initial time at which an output-limiting symptom occurred (min) x 6.162 - abdominal wall fat thickness $(\mathrm{mm}) \times 17.155+967.995$; i.e., larger number of IRO means thinner thickness of the fat of the abdominal wall. In the present study, we considered $0 \mathrm{~min}$ as the initial time at which an output-limiting symptom occurred and compared it to the actual observed output.

The primary endpoint was toxicity and locoregional tumor control and the main objective of the present study was to identify pretreatment clinical parameters that predict $\mathrm{pCR}$ and progressive disease (PD). We retrospectively evaluated whether or not our predictive formula of output-limiting symptoms could predict pCR and PD at the beginning of this modality.

\section{Materials and methods}

The present study included 81 consecutive patients who were diagnosed with primary rectal adenocarcinoma localized in the rectum [up to $12 \mathrm{~cm}$ from the anal verge: The National Cancer Institute Rectal Cancer Focus Group has defined the rectum as anything remaining within $12 \mathrm{~cm}$ from the anal verge (19)] between December 2011 and May 2015. All patients received pre- and post-treatment diagnostic examinations, including computed tomography (CT), positron emission tomography/CT (PET/CT), and magnetic resonance imaging (MRI) at Hidaka Hospital. The tumor extent and location were classified according to the tumor-node-metastasis (TNM) staging (20).

All patients underwent NACR with concurrent thermal therapy at Hidaka Hospital. Surgeries were performed at the Department of General Surgical Science at Gunma University or the Division of Surgery at Hidaka Hospital. Each resected specimen was histologically evaluated in the Department of Pathology at Gunma University. The present study was approved by the Ethics Committees of Hidaka Hospital and Gunma University. Each patient provided written informed consent.

Chemoradiotherapy. Intensity-modulated radiotherapy (IMRT) was conventionally administered once daily

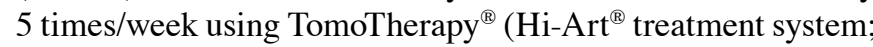
Accuray ${ }^{\circledR}$ ). For neoadjuvant radiotherapy, 50 Gy of radiotherapy was administered to the posterior pelvis in $252-$ Gy fractions. Concurrent neoadjuvant chemotherapy was administered in 5-day courses during the first through fifth week of NACR. Capecitabine (Cap) was administered orally at a dose of $1,700 \mathrm{mg} / \mathrm{m}^{2} /$ day for 5 days/week. Patients received Cap throughout the radiation therapy course, beginning and ending on the first and last days of radiation therapy administration, respectively.

Thermal therapy. Thermal treatment was performed using the Thermotron-RF8 (Yamamoto Vinita Co., Ltd., Osaka, Japan) and administered once a week for 5 weeks during a 50-min irradiation. Precise thermal therapy methods have been previously described $(18,21-23)$.

Objective response evaluation. The timing of objective response evaluations according to the Response Evaluation Criteria in Solid Tumors (RECIST) using MRI and PET/CT varied from weeks 2-18 after completion of NACR with concurrent thermal therapy, with a median time of 8 weeks (24). We classified patient responses as follows: complete response (CR), which describes total resolution of the lesions; partial response (PR), which describes a $30 \%$ decrease in the sum of the diameters of the lesions; stable disease (SD), which describes changes between a $30 \%$ decrease and $20 \%$ increase; and PD, which describes an increase of at least $20 \%$ in the sum of the diameters of the lesions or new distant metastasis. We evaluated CR as the disappearance of the tumor on PET/CT and MRI and a positive to negative change by PET/CT. The CRPD group included patients who experienced local CRs, although new distant metastases appeared. Adverse effects of these treatments were evaluated based on the criteria defined by the Common Terminology Criteria for Adverse Events (Ver.4.0) (25).

Pathology. Resected specimens $(n=54)$ were evaluated according to the Japanese Classification of Colorectal Carcinoma. According to this criteria, pathological grade 0 tumors have no fibrosis. Grade 1 tumors exhibit denaturation and necrosis of cancer cells in approximately $<1 / 3$ of the tumor (grade 1a) or denaturation and necrosis in $<2 / 3$ of cancer cells plus fusion in $>1 / 3$ of the tumor (grade $1 \mathrm{~b}$ ). Grade 2 tumors exhibit significant denaturation, necrosis, fusion and loss in $>2 / 3$ of the tumor. In grade 3 tumors [pathological complete response (pCR)], no cancer cell is observed in both primary and regional lymph nodes (19). The pathological grade 1-OPD group included patients in whom local pathological grade 1 to 0 had resolved even though new distant metastases appeared.

Statistical analysis. SPSS Statistics (IBM, Armonk, NY, USA) version 21 was used to analyze all data. Mean values were compared using Student's t-tests. Categorical data were analyzed using the $\chi^{2}$ test statistics. All reported P-values are two-tailed and were considered significant when $\mathrm{P}<0.05$.

From the thickness of the fat of the abdominal wall (mm), IRO Watt and RO difference Watt at their first thermal treatment were determined using the formulas below as follows:

IRO $($ Watt $)=967.995-$ abdominal wall fat thickness $(\mathrm{mm}) \times 17.155$

Average RO difference at the first thermal treatment (Watt $/ \mathrm{min})=$ average actual observed $\mathrm{RO}(\mathrm{Watt} / \mathrm{min})$ at the first thermal treatment IRO (Watt)

Average RO difference after treatment completion (Watt $/ \mathrm{min} / 5)=$ average actual observed RO (Watt/min) at treatment completion IRO (Watt)

For predicted IRO, the quartiles were $\leq 635,636$ to 720,721 to 792 and $\geq 793$ Watt. For RO differences, the quartiles were $\leq-153,-152$ to $-77,-76$ to 76 , and $\geq 77$ Watt at the first thermal treatment and $\leq-135,-134$ to $-32,-31$ to 132 and $\geq 133$ Watt after treatment completion.

\section{Results}

Table I contains the characteristics of the patients. Of the 81 consecutive patients, 56 received NACR with concurrent 
Table I. Patient characteristics.

\begin{tabular}{lc}
\hline Patient characteristics & Data \\
\hline Total no. of patients & 81 \\
Age (years) & \\
Median & 62 \\
Range & $33-89$ \\
Gender, n (\%) & \\
Female & $20(24.7)$ \\
Male & $61(75.3)$ \\
\end{tabular}

Distance to anal verge $(\mathrm{cm}), \mathrm{n}(\%)$

$\begin{array}{ll}0-3.0 & 55(67.9) \\ 3.1-5.0 & 15(18.5) \\ 5.1- & 11(13.6)\end{array}$

Tumor location, n (\%)

$\mathrm{Ra}$

$10(12.3)$

$\mathrm{Rb}$

$46(56.8)$

$\mathrm{RbP}$

$25(30.9)$

Tumor stage, $\mathrm{n}(\%)$

$\mathrm{T} 2$

$20(24.7)$

T3

45 (55.6)

$16(19.8)$

$\mathrm{T} 4$

$40(49.4)$

38 (46.9)

1 (1.2)

N3

Pretreatment TNM stage, n (\%)

Stage 1

12 (14.8)

Stage 2

24 (29.6)

38 (46.9)

7 (8.6)

Stage 4

38 (46.9)

36 (44.4)

$6(7.4)$

$1(1.2)$

Undifferentiated

$15(18.5)$

$13(16.0)$

$6(7.4)$

25 (30.9)
Table I. Continued.

\begin{tabular}{ll}
\hline Patient characteristics & Data \\
\hline $\begin{array}{l}\text { Clinical response after completion } \\
\text { of treatment, } \mathrm{n}(\%)\end{array}$ \\
CR \\
PR & $26(32.1)$ \\
SD & $32(39.5)$ \\
PD & $10(12.3)$ \\
\hline
\end{tabular}

TNM, tumor-node-metastasis; APR, abdominoperineal resection; LAR, low anterior resection; sLAR, super low anterior resection; ISR, intersphincteric resection; $\mathrm{CR}$, complete response; $\mathrm{PR}$, partial response; $\mathrm{SD}$, stable disease; $\mathrm{PD}$, progressive disease.

thermal therapy followed by surgery. In total, 54 tumors were resected and evaluated for pathological responses. Two patients did not have their tumors resected since the tumors were widespread, and 25 patients did not undergo surgery. Reasons for not undergoing surgery included the surgery itself after CR $(n=4)$, permanent ostomy $(n=7)$, poor general conditions (age and various complications; $n=6$ ) and PD $(n=8)$, which included 3 lung metastases, 2 liver metastases, and growth of tumors or lymph nodes in 3 patients. The timing of surgical resections varied from 8 to 42 weeks after NACR and thermal therapy, with a median of 15 weeks after treatment completion. The median distance to the anal verge was $3.0 \mathrm{~cm}$ (range, $0-12 \mathrm{~cm}$ ). We avoided permanent ostomy in $41 / 56$ patients $(73.2 \%)$.

Reduced tumor burden was achieved in 37/54 patients $(68.5 \%)$, specifically in $10 / 15$ patients $(66.6 \%)$ with preoperative T2 lesions, $20 / 31$ patients $(64.5 \%)$ with T3 lesions and $7 / 8$ patients $(87.5 \%)$ with T4 lesions. Sixteen of the 54 patients $(29.6 \%)$ had postoperative yT0 lesions.

NACR with concurrent thermal therapy was well-tolerated, with $96.3 \%$ of our patients receiving the full dose of chemotherapy and $100 \%$ receiving the full dose of radiotherapy and 5 cycles of thermal therapy. Sixty-three patients (77.8\%) and 18 patients $(22.2 \%)$ received thermal treatments with and without standardized power escalation principles, which we called neothermia, respectively (21).

In 81 tested patients, CR, PR, SD and PD with the RECIST criteria were shown in $32.1,39.5,12.3$ and $16.0 \%$ of the patients, respectively (Table I). Table II displays the treatment response results for 81 patients with rectal cancer after completion of NACR with concurrent thermal therapy according to tumor stage, lymph node involvement, distant metastasis and pretreatment tumor-node-metastasis (TNM) stage. In 54 resected tumor samples, pCR grade 3 , grade 2 , grade 1-0, grade 1-0PD was found in 20.4, 37.0, 35.2 and $7.4 \%$ of the samples, respectively. The PD ratio included clinical PD and pathological grade 1-0PD. Five patients (25.0\%) and 3 patients $(15.0 \%)$ who were diagnosed with pretreatment T2 tumors achieved pCRs and CRs, respectively, while 1 patient $(6.2 \%)$ with T4 tumor achieved CR. Four patients $(33.3 \%)$, and 3 patients $(25.0 \%)$ who were diagnosed with pretreatment pTNM stage 1 tumors achieved pCRs and CRs, respectively, 
Table II. Treatment response results after completion of NACR with concurrent thermal therapy, according to tumor stages, lymph node involvement, distant metastasis and pretreatment TNM stages in 81 patients with rectal cancer.

\begin{tabular}{|c|c|c|c|c|c|c|c|}
\hline & Grade 3 & Grade 2 & Grade 1-0 & CR & PR-SD & PD & \\
\hline & $\mathrm{n}(\%)$ & $\mathrm{n}(\%)$ & $\mathrm{n}(\%)$ & $\mathrm{n}(\%)$ & $\mathrm{n}(\%)$ & $\mathrm{n}(\%)$ & Total \\
\hline $\mathrm{T} 2$ & $5(25.0)$ & $6(30.0)$ & $3(15.0)$ & $3(15.0)$ & $1(5.0)$ & $2(10.0)$ & 20 \\
\hline $\mathrm{T} 3$ & $6(13.3)$ & $11(24.4)$ & $12(26.7)$ & $1(2.2)$ & 7 (15.6) & $8(17.8)$ & 45 \\
\hline $\mathrm{T} 4$ & $0(0.0)$ & $3(18.8)$ & $4(25.0)$ & $1(6.2)$ & $4(25.0)$ & $4(25.0)$ & 16 \\
\hline $\mathrm{N}-$ & $8(20.0)$ & $12(30.0)$ & $6(15.0)$ & $4(10.0)$ & $6(15.0)$ & $4(10.0)$ & 40 \\
\hline $\mathrm{N}+$ & $3(7.3)$ & $8(19.5)$ & 13 (31.7) & $1(2.4)$ & $6(14.6)$ & $10(24.4)$ & 41 \\
\hline $\mathrm{M}(-)$ & $11(14.9)$ & $19(25.7)$ & $18(24.3)$ & $5(6.8)$ & $12(16.2)$ & $9(12.2)$ & 74 \\
\hline $\mathrm{M}(+)$ & $0(0.0)$ & $1(14.3)$ & $1(14.3)$ & $0(0.0)$ & $0(0.0)$ & $5(71.4)$ & 7 \\
\hline Stage 1 & $4(33.3)$ & $2(16.7)$ & $2(16.7)$ & $3(25.0)$ & $0(0.0)$ & $1(8.3)$ & 12 \\
\hline Stage 2 & 4 (16.7) & $9(37.5)$ & $3(12.5)$ & $1(4.2)$ & $6(25.0)$ & $1(4.2)$ & 24 \\
\hline Stage 3 & $3(7.9)$ & $8(21.1)$ & $13(34.2)$ & $1(2.6)$ & $6(15.8)$ & $7(18.4)$ & 38 \\
\hline Stage 4 & $0(0.0)$ & $1(14.3)$ & $1(14.3)$ & $0(0.0)$ & $0(0.0)$ & $5(71.4)$ & 7 \\
\hline Total & 11 (13.6) & $20(24.7)$ & $19(23.5)$ & $5(6.2)$ & $12(14.8)$ & $14(17.3)$ & 81 \\
\hline
\end{tabular}

NACR, neoadjuvant chemoradiation; TNM, tumor-node-metastasis, CR, complete response; PR, partial response; SD, stable disease; PD, progressive disease.

Table III. Results according to the frequency of RF-induced output-limiting symptoms.

\begin{tabular}{|c|c|c|c|c|c|c|c|}
\hline \multicolumn{2}{|c|}{ Patients } & \multirow{2}{*}{$\frac{\text { Grade } 3}{\mathrm{n}(\%)}$} & \multirow{2}{*}{$\frac{\text { Grade } 2}{\mathrm{n}(\%)}$} & \multirow{2}{*}{$\frac{\text { Grade 1-0 }}{\mathrm{n}(\%)}$} & \multirow{2}{*}{$\frac{\mathrm{CR}}{\mathrm{n}(\%)}$} & \multirow{2}{*}{$\frac{\text { PR-SD }}{\mathrm{n}(\%)}$} & \multirow{2}{*}{$\frac{\mathrm{PD}}{\mathrm{n}(\%)}$} \\
\hline Scores & $\mathrm{N}$ & & & & & & \\
\hline $0 / 5$ & 8 & $2(25.0)$ & $1(12.5)$ & $2(25.0)$ & $0(0.0)$ & $2(25.0)$ & $1(12.5)$ \\
\hline $1 / 5$ & 38 & $6(15.8)$ & $8(21.1)$ & $10(26.3)$ & $2(5.3)$ & $6(15.8)$ & $6(15.8)$ \\
\hline $2 / 5$ & 15 & $2(13.3)$ & $3(20.0)$ & $2(13.3)$ & $2(13.3)$ & $3(20.0)$ & $3(20.0)$ \\
\hline $3 / 5$ & 6 & $0(0.0)$ & $3(50.0)$ & $1(16.7)$ & $0(0.0)$ & $1(16.7)$ & $1(16.7)$ \\
\hline $4 / 5$ & 11 & $1(9.1)$ & $4(36.4)$ & $2(18.2)$ & $1(9.1)$ & $1(9.1)$ & $2(18.2)$ \\
\hline $5 / 5$ & 3 & $0(0.0)$ & $1(33.3)$ & $1(33.3)$ & $0(0.0)$ & $0(0.0)$ & $1(33.3)$ \\
\hline Total & 81 & $11(13.6)$ & $20(24.7)$ & $18(22.2)$ & $5(6.2)$ & $13(16.0)$ & $14(17.3)$ \\
\hline
\end{tabular}

0/5, No output-limiting symptoms during the 5 thermal therapies; $5 / 5$, output-limiting symptoms occurred during each thermal therapy. RF, radiofrequency; $\mathrm{CR}$, complete response; $\mathrm{PR}$, partial response; $\mathrm{SD}$, stable disease; PD, progressive disease.

while 5 patients $(71.4 \%)$ diagnosed with TNM stage 4 disease experienced PD.

Table III displays the treatment response results according to the frequency of RF-induced output-limiting symptoms during the 5 thermal treatments. Patients who scored $0 / 5$ experienced no output-limiting symptoms during the thermal treatments, while those who scored $5 / 5$ experienced output-limiting symptoms during each thermal treatment. The highest pCR rate $(25.0 \%)$ was seen in patients who had no RF-induced output-limiting symptoms during the thermal treatments.

As for RF-induced output-limiting symptoms during thermal therapy, 69 patients (85.2\%) experienced RF-induced output-limiting symptoms, with 54 of those $(66.7 \%)$ experiencing pain, including 4 patients $(4.9 \%)$ who stopped RF due to severe symptoms, 8 experiencing skin discomfort,
5 experiencing subcutaneous induration, 1 experiencing micturition desire and 1 experiencing cold sensations.

Table IV summarizes the toxicity incidence among the 81 patients. Grade 3 toxicities were observed in 7/81 patients (8.6\%), with 1 patient experiencing palmar-plantar erythrodysesthesia syndrome, 3 experiencing anal mucositis, 2 experiencing diarrhea and 1 experiencing anemia.

Fig. 1 shows the treatment response results according to the predicted IRO (Watt) of output-limiting symptoms. The highest proportion of patients with grade 3 disease (21.2\%) was in the upper quartile ( $\geq 793$ Watt), followed by $15.0 \%$ in the lowest quartile ( $\leq 635$ Watt).

Fig. 2 shows the average of the RO difference (Watt) (Fig. 2A) and the treatment responses at the first RF thermal therapy (Fig. 2B). There was a significant difference in the RO difference between patients with pathological grade 1-0PD 
Table IV. Summary of the toxicity in response to NACR with concurrent thermal therapy in 81 patients.

\begin{tabular}{|c|c|c|c|c|c|}
\hline & Negative response (-) & Grade 1 & Grade 2 & Grade 3 & \\
\hline Toxicities & $\mathrm{n}(\%)$ & $\mathrm{n}(\%)$ & $\mathrm{n}(\%)$ & $\mathrm{n}(\%)$ & Total \\
\hline $\begin{array}{l}\text { Palmar-plantar erythrodysesthesia } \\
\text { syndrome }\end{array}$ & $20(24.7)$ & $46(56.8)$ & $14(17.3)$ & $1(1.2)$ & 81 \\
\hline Peripheral sensory neuropathy & $66(81.5)$ & $15(18.5)$ & $0(0.0)$ & $0(0.0)$ & 81 \\
\hline Anal mucositis & $14(17.3)$ & $33(40.7)$ & $31(38.3)$ & $3(3.7)$ & 81 \\
\hline Nausea & $68(84.0)$ & $10(12.3)$ & $3(3.7)$ & $0(0.0)$ & 81 \\
\hline Anorexia & $75(92.6)$ & $4(4.9)$ & $2(2.5)$ & $0(0.0)$ & 81 \\
\hline Diarrhea & $32(39.5)$ & $40(49.4)$ & $7(8.6)$ & $2(2.5)$ & 81 \\
\hline Fatigue & $76(93.8)$ & $5(6.2)$ & $0(0.0)$ & $0(0.0)$ & 81 \\
\hline White blood cell count decrease & $58(71.6)$ & $11(13.6)$ & $12(14.8)$ & $0(0.0)$ & 81 \\
\hline Anemia & $51(63.0)$ & $22(27.2)$ & $7(8.6)$ & $1(1.2)$ & 81 \\
\hline Platelet count decrease & $64(79.0)$ & $16(19.8)$ & $1(1.2)$ & $0(0.0)$ & 81 \\
\hline
\end{tabular}

NACR, neoadjuvant chemoradiation.

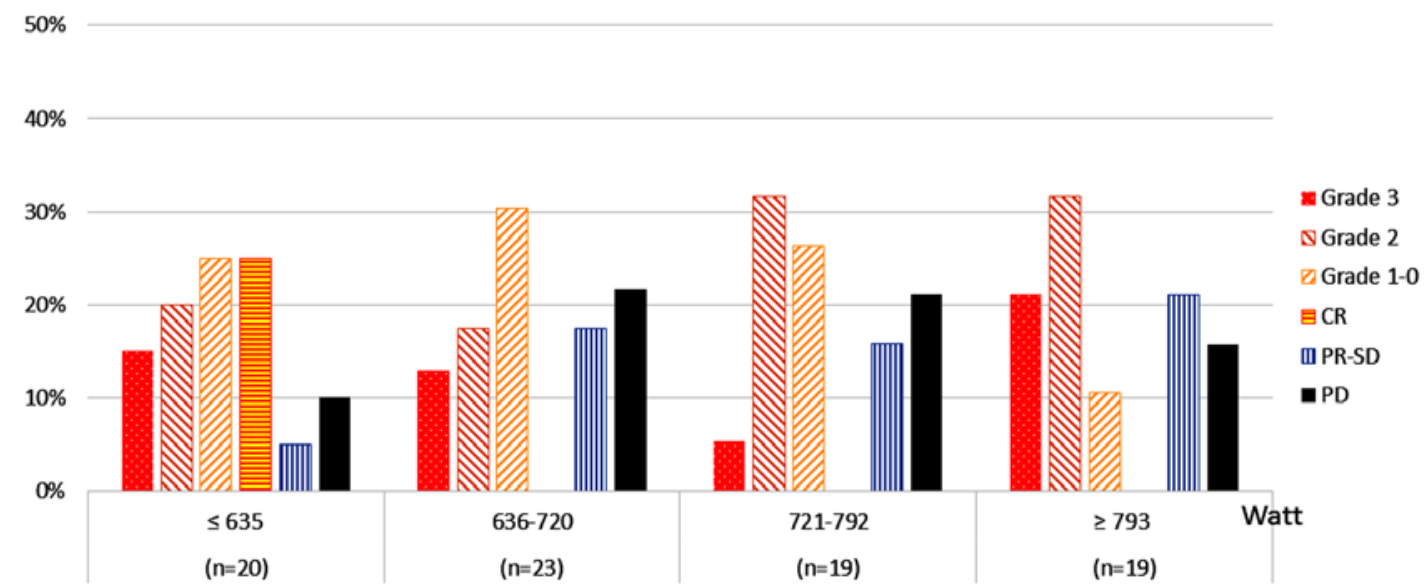

Figure 1. Treatment response results according to the predicted initial RF output (IRO) (Watt) of output-limiting symptoms.
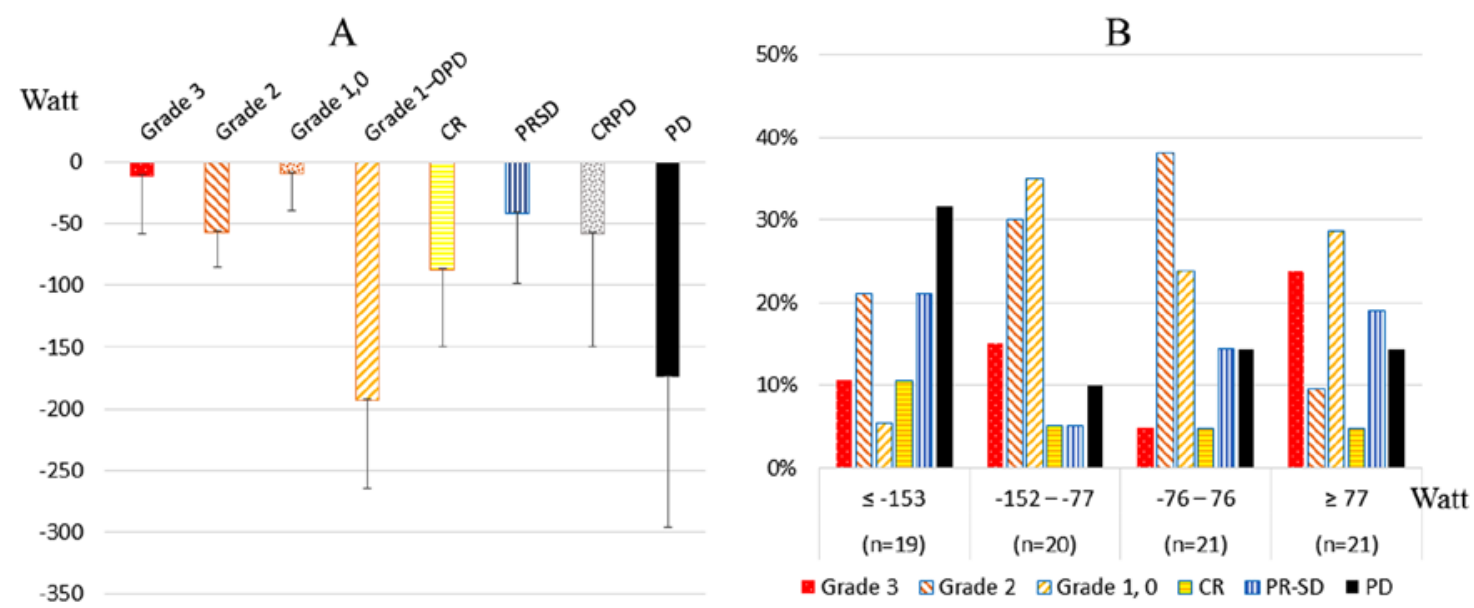

Figure 2. Average RO difference (Watt) and treatment response at the first radiofrequency (RF) thermal therapy. (A) Average RO difference. (B) Treatment response.

and grade $1-0(\mathrm{p}=0.021)$. All patients with PD had negative scores of RF outputs, as PD patients did not receive increased
RF output over the predictive output. The highest proportion of patients with grade 3 disease $(23.8 \%)$ was in the upper 
A

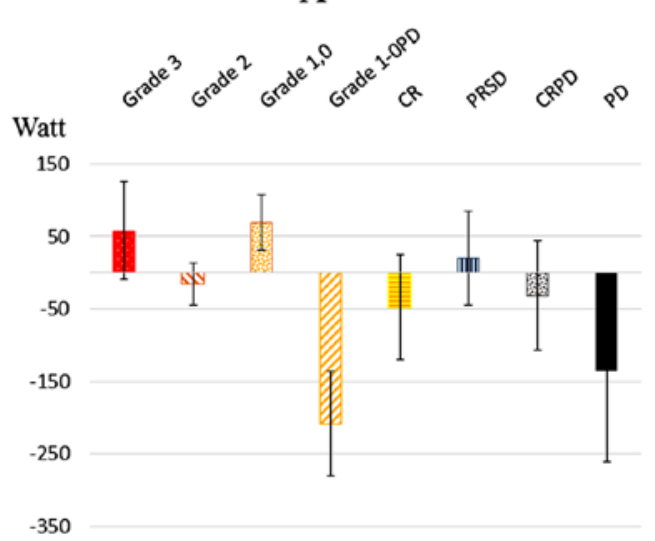

B

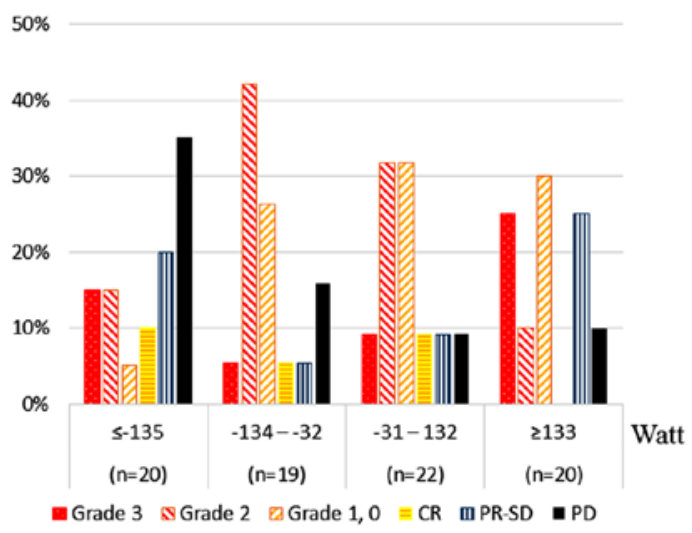

Figure 3. Average RO difference (Watt) and treatment response after the fifth thermal therapy. (A) Average RO difference. (B) Treatment response.

A

Predictive IRO: $\leq 635$ Watt

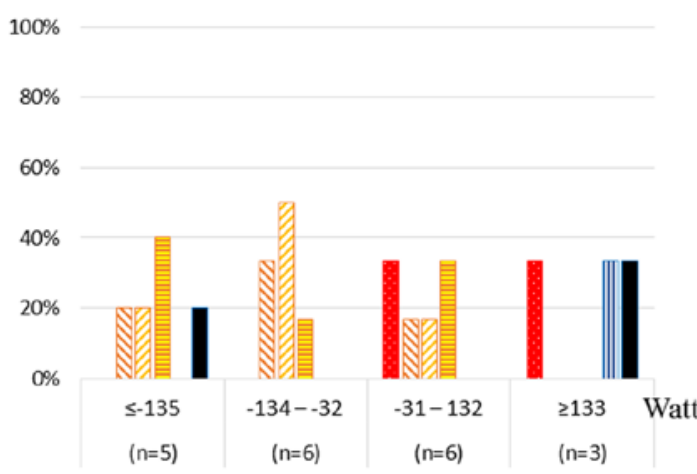

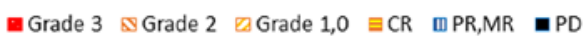

B

Predictive IRO: 636 - 720 Watt

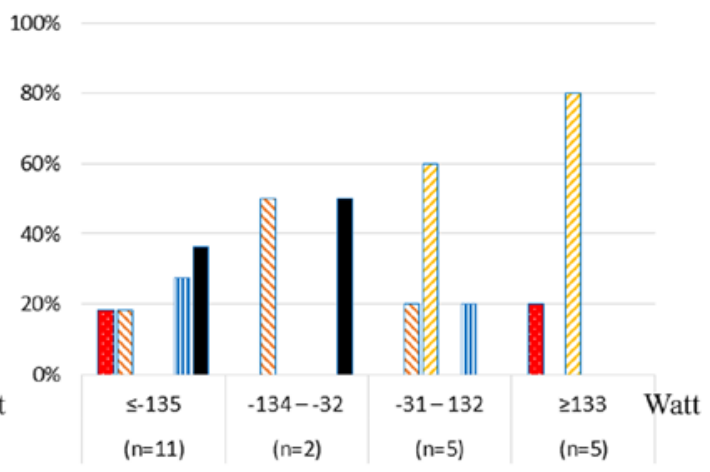

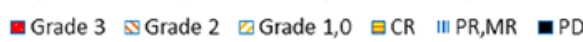

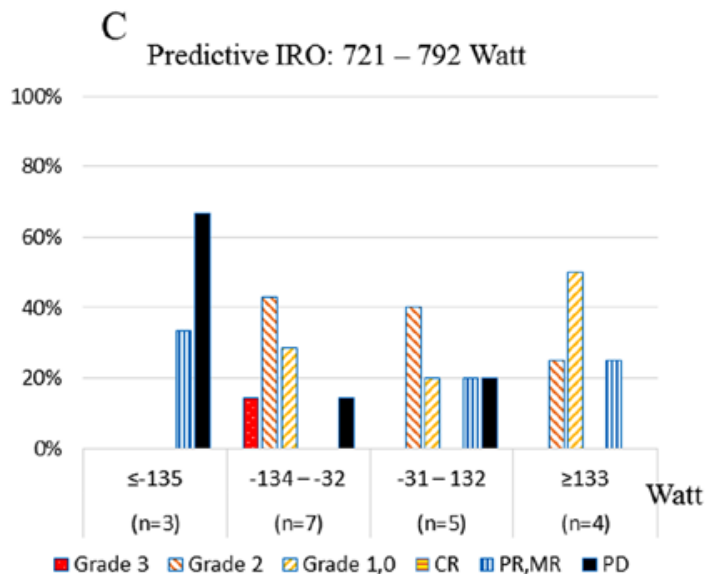

$\mathrm{D}$

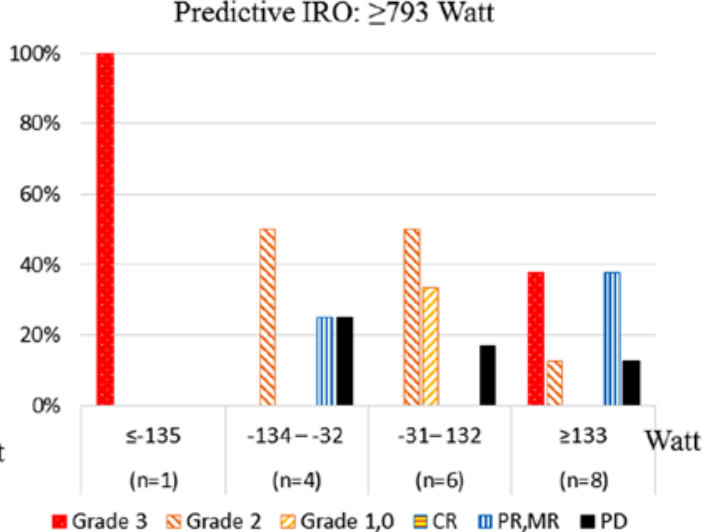

Figure 4. Correlations between predicted initial RF outputs (IROs) and the RO differences (Watt) or treatment responses after the fifth thermal therapy. (A) Predicted IRO, $\leq 635$ Watt. (B) Predicted IRO, 636-720 Watt. (C) Predicted IRO: 721-792 Watt. (D) Predicted IRO, $\geq 793$ Watt.

quartile ( $\geq 77$ Watt) and the highest proportion of patients with PD $(31.6 \%)$ was in the lowest quartile ( $\leq-153$ Watt).

Fig. 3 shows the average RO difference (Watt) (Fig. 3A) and treatment response after the fifth thermal treatment (Fig. 3B). There were significant differences between patients with grade 3 , grade 2 and grade 1-0 disease and patients with pathological grade 1-0PD $(p=0.046, p=0.016$ and $p=0.005$, respectively). There was a weak relationship between patients with grade 3 disease and all patients with PD $(p=0.054)$. The highest proportion of patients with grade 3 disease $(25.0 \%)$ was in the upper quartile ( $\geq 133 \mathrm{Watt}$ ), and the highest proportion of patients with PD $(35.0 \%)$ was in the lowest quartile ( $\leq-135$ Watt).

Fig. 4 shows the correlations between both the predicted IRO and the RO difference (Watt) and treatment response after the fifth thermal treatment.

The highest proportion of patients with grade 3 disease $(37.5 \%)$ were in the upper quartiles (predicted IRO $\geq 793$ Watt 
A

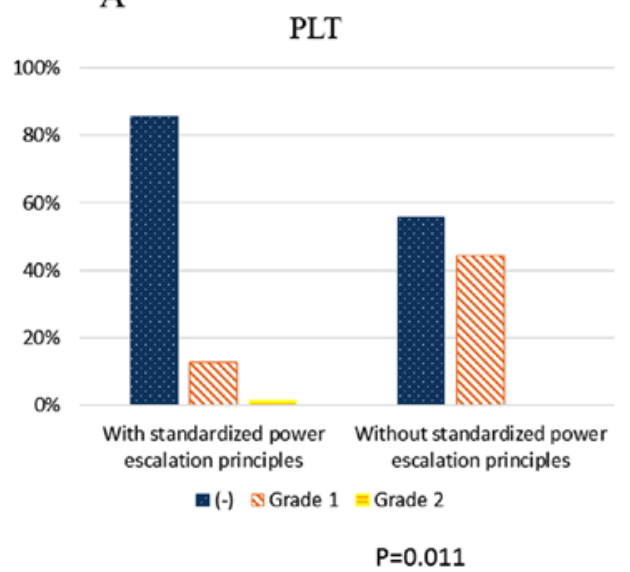

B

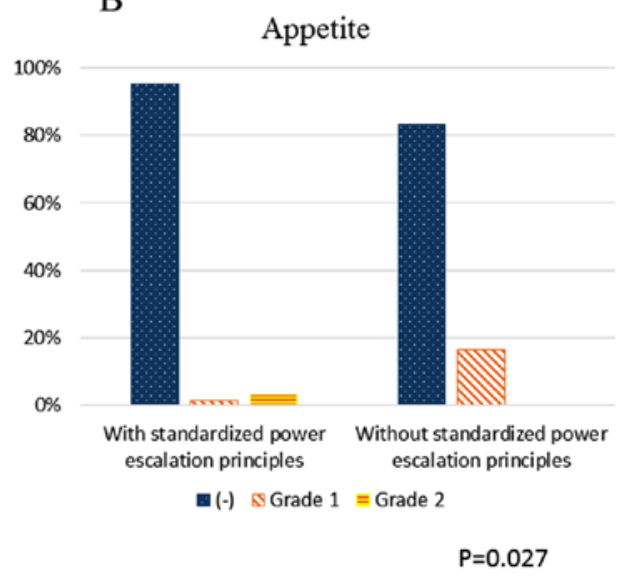

Figure 5. Toxicity (A) platelet count decrease and (B) anorexia in patients receiving thermal therapy with or without standardized power escalation principles.

and predicted IRO with $\geq 133$ Watt) (Fig. 4D), and the highest proportion of patients with PD were in the predicted IRO 721-792 Watt quartile and the RO difference $\leq-135$ Watt quartile (Fig. 4C).

Fig. 5 shows the toxicities in patients receiving thermal treatment with or without standardized power escalation principles. There was no significant difference between patients who received treatments with or without standardized power escalation principles, with the exception of platelet (PLT) and anorexia, which patients who received treatment with standardized power escalation principles experienced with significant less frequency ( $\mathrm{p}=0.011$ and $\mathrm{p}=0.027$, respectively).

\section{Discussion}

Although numerous studies support the use of capecitabine or infusional 5-FU, which are potentially radiosensitizing agents (26-28). as a standard of care in the neoadjuvant treatment of rectal cancer, the optimal preoperative chemotherapy regimen and radiation dose as a combined therapy for patients with rectal cancer are unknown. Recently, the National Surgical Adjuvant Breast and Bowel Project published its final study, in which the neoadjuvant Cap use was comparable to continuous 5-FU infusion when combined with radiation therapy ( $45 \mathrm{~Gy} / 25$ fractions) in 1,608 patients with stage II or III rectal cancer, and the addition of oxaliplatin (OXA) did not provide additional benefits with respect to toxicity $(29,30)$. The reported pCR rate was $20.7 \%$ for patients receiving Cap $\left(825 \mathrm{mg} / \mathrm{m}^{2}\right)$ 7 days a week beginning and ending on the first and last days of radiation therapy, respectively, which was similar to the rates in other studies $(\sim 15 \%)(2,3,15)$.

Craven et al reported results using similar regimens to the one described in the present study (radiation, $45 \mathrm{~Gy} / 25$ fractions; Cap, $900 \mathrm{mg} / \mathrm{m}^{2}$ for 5 days/week vs. 7 days/week) in 70 patients with rectal cancer. The pCR and progressive disease (PD) rates were 9.2 and 6\%, respectively. Sixty-two patients (88.6\%) received the full dose of Cap without suffering significant grade 3 or 4 toxicities. Three patients (4.3\%) had to discontinue Cap due to acute toxicities. Sixty-seven patients (96\%) received the full 45-Gy dose of radiotherapy. Three patients (4.3\%) suffered grade 3 diarrhea, while 1 patient developed severe abdominal pain and diarrhea.
Of the 65 patients who underwent resections, 33 were anterior resections, 26 were abdominoperineal resections, 5 were pelvic exenterations and in 33/64 (51.5\%) the anus was preserved (31).

Gérard et al compared the Cap 45 group, which received $45 \mathrm{~Gy} / 25$ fractions with concurrent $800 \mathrm{mg} / \mathrm{m}^{2}$ Cap twice daily 5 days/week, and the combined Cap and OXA group, which received $50 \mathrm{~Gy} / 25$ fractions with $800 \mathrm{mg} / \mathrm{m}^{2}$ Cap twice daily 5 days/week and $50 \mathrm{mg} / \mathrm{m}^{2}$ OXA once weekly. The present study of 597 patients with rectal cancer reported pCR rates of $13.9 \%$ for the Cap 45 group and $19.2 \%$ for the Cap + OXA group (32).

Positive outcomes due to IMRT plus Cap treatment have been observed, with $\mathrm{pCR}$ rates ranging from $14.1 \%$ to $30.6 \%$ in patients with grade 3 disease, who comprised $11.1 \%$ to $17.6 \%$ of the study populations (33-35), but these studies did not mention cases of PD. Lu et al (36) only reported a pCR in $20 \%$ of the cases with a $22 \%$ rate of grade 3 toxicity, and PD in $17 \%$ of the cases. Studies with controlled trials also did not mention PD. Thus, it is likely that PD cases were not analyzed in these studies.

To the best of our knowledge, Hernando-Requejo et al reported excellent pCR rates using the concomitant-boost IMRT dose fractionation scheme (35). Seventy-four patients were treated with concomitant-boost IMRT $(57.5 \mathrm{~Gy}$ in 23 fractions and concurrent $825 \mathrm{mg} / \mathrm{m}^{2}$ Cap bid), and the pCR and grade 3 toxicity rates were 30.6 and $17.6 \%$, respectively.

Before the year 2000, there was no standardized thermal dose or standard hyperthermia treatment. Although the results were not comparable, the $\mathrm{pCR}$ rates were reported to range from 10 to $14 \%$, in populations with $14 \%$ PD by adding hyperthermia to chemoradiotherapy in patients with rectal cancer $(37,38)$. Since 2000, trials by the International Agency of Atomic Energy (IAAE) and Issels et al failed to show a synergistic effects between hyperthermia and radiotherapy (39-41).

Schroeder et al reported a retrospective study comparing neoadjuvant radiation with concurrent 5-FU-based chemotherapy with $(\mathrm{n}=61)$ and without $(\mathrm{n}=45)$ hyperthermia (90 min, 4-6 times) in 106 patients with rectal cancer, and pCR was achieved in $6.7 \%$ of the patients in the chemoradiation group and $16.4 \%$ of the patients in the hyperthermia group. The rate of sphincter-sparing surgery was $57 \%$ in the hyperthermo-radiochemotherapy group in comparison to 
$35 \%$ in the radiochemotherapy group, while, our rate of sphincter-sparing surgery was $73.2 \%$. However, a total of 21 out of 61 patients (34.4\%) discontinued hyperthermia within the first three treatments (42).

Maluta et al recently reported that hyperthermia plus chemoradiotherapy $\left(200 \mathrm{mg} / \mathrm{m}^{2}\right.$ continuous 5 -FU infusion for 6 weeks plus weekly $45 \mathrm{mg} / \mathrm{m}^{2} \mathrm{OXA}$, and $50 \mathrm{~Gy}$ in 2-Gy fractions for 5 weeks plus a 10-Gy boost) resulted in pCRs for 18 out of 76 patients (23.6\%), and 4/76 patients (5.2\%) developed PD (43).

This series of patients receiving tumor resection and a 5-day/week schedule of Cap and radiotherapy with concurrent thermal therapy, shows higher compliance (96.3\%), lower toxicity $(8.6 \%)$, a better rate for preserving the anus (73.2\%), better tumor burden (68.5\%), and fairly good local control (20.4\%) compared to previous studies.

We noticed that the rate of PD (17.3\%) was higher than that of pCR in this series. Therefore, the specific patients who should be indicated to receive this therapy modality should be clarified. If we can discover or predict patients who received good outcomes using this treatment modality, this may add value in a clinical setting.

We reported that correlations between RF output and skin temperature from that RF output could be divided into three groups: low, median and high output, according to the occurrence of the output-limiting symptoms. From combination analyses of RF output and temperature output, patient temperature in the low RF output group did not increase. No patients achieved pCRs, and there was a high rate of PD. We think that these patients cannot respond to NACR with concurrent thermal therapy, and they possibly cannot respond to NACR alone. From these results and with the low pCR rate observed in these patients, additional and/or synergistic effects with NACR with concurrent thermal therapy were not observed. Consequently, the thermal therapy may offset the NACR effects in these patients. From our results, we found that patients with cT2, T3 and N0 lesions who were pretreated obtained good responses using this modality. However, those with $\mathrm{T} 4, \mathrm{~N}(+)$ or $\mathrm{M}(+)$ lesions did not. This was similar to the results observed in other studies.

We also demonstrated in the present study that patients with PD actually could not receive higher RF outputs than the predicted output. We indicated the patient groups predicted to be able to receive more output that actually could receive more output than the predicted output as well as those who were predicted to receive lower to moderate output and could not receive more than the predicted output. The former group had a $37.5 \%$ pCR rate and the latter group had a $66.7 \%$ rate of PD. From previous and present data, we speculate that RF thermal therapy may offset the chemoradiation effects in patients who could receive more than the predicted output. Adding thermal therapy as a multimodality therapy to NACR has a potential filter effect on patients based on whether they experience potency with lower predicted outputs or higher predicted outputs as well as lower or higher RO differences. Thermal therapy, as a multidisciplinary therapy, may be used to evaluate patients that should be treated with NACR to determine whether they may experience true $\mathrm{pCR}$ or fallacious $\mathrm{PD}$.

At present, unfortunately, we do not understand these mechanisms. One explanation for our results concerning the filter effects of RF thermal therapy is that RF thermal therapy and IMRT which provide electromagnetic treatment affect cancer cells with low energy and low-frequency waves (8-MHz) or high energy and high-frequency waves $\left(>3 \times 10^{19} \mathrm{~Hz}\right)$, respectively. Further study is needed to confirm these preliminary data in the future.

The need for suitable markers for the identification of patients who respond to cancer treatment is not limited to NACR with concurrent thermal therapy, and it is essential to reliably assess CRs and PD before or after completion of NACR treatment. Therefore, developing tools that predict responses has become exceedingly important, and a large number of studies have evaluated molecular parameters (44-46). To date, none have been validated in multi-institutional prospective trials. We may complete further studies to find suitable markers that may fit more with our predictive formula and offer more precise response to treatment assessments of this modality.

In conclusion, this treatment modality was beneficial for patients with $\mathrm{T} 2, \mathrm{~T} 3$ and N0 rectal cancer in order to avoid permanent ostomy, and the predictive formula for output-limiting symptoms induced by RF is a good tool to predict CRs or PD. This formula may be able to identify patients in the clinical setting using chemoradiation treatment markers. These data suggest that RF with low/high output conditions, were correlated with output-limiting symptoms, which had a good or bad synergistic effect with chemoradiation regimens. Our predictive equation for the initial energy output at which output-limiting symptoms occur may also be able to use early assessment of treatment efficacy, and as a result, it can be used to decide on the continuation or cessation of this treatment modality.

The present study does have some limitations. We used a small sample size. Due to this, we did not have a group that received radiation therapy with concurrent Cap. We also did not perform long-term follow-up of the patients after therapy. Therefore, further studies should be performed to confirm these results.

\section{References}

1. Bosset JF, Calais G, Mineur L, Maingon P, Stojanovic-Rundic S, Bensadoun RJ, Bardet E, Beny A, Ollier JC, Bolla M, et al; EORTC Radiation Oncology Group: Fluorouracil-based adjuvant chemotherapy after preoperative chemoradiotherapy in rectal cancer: Long-term results of the EORTC 22921 randomised study. Lancet Oncol 15: 184-190, 2014.

2. Sauer R, Liersch T, Merkel S, Fietkau R, Hohenberger W, Hess C, Becker H, Raab HR, Villanueva MT, Witzigmann H, et al: Preoperative versus postoperative chemoradiotherapy for locally advanced rectal cancer: Results of the German CAO/ARO/AIO-94 randomized phase III trial after a median follow-up of 11 years. J Clin Oncol 30: 1926-1933, 2012.

3. Gérard JP, Conroy T, Bonnetain F, Bouché O, Chapet O, Closon-Dejardin MT, Untereiner M, Leduc B, Francois E, Maurel J, et al: Preoperative radiotherapy with or without concurrent fluorouracil and leucovorin in T3-4 rectal cancers: Results of FFCD 9203. J Clin Oncol 24: 4620-4625, 2006.

4. Park JH, Yoon SM, Yu CS, Kim JH, Kim TW and Kim JC: Randomized phase 3 trial comparing preoperative and postoperative chemoradiotherapy with capecitabine for locally advanced rectal cancer. Cancer 117: 3703-3712, 2011.

5. Peeters KC, Marijnen CA, Nagtegaal ID, Kranenbarg EK, Putter H, Wiggers T, Rutten H, Pahlman L, Glimelius B, Leer JW, et al; Dutch Colorectal Cancer Group: The TME trial after a median follow-up of 6 years: Increased local control but no survival benefit in irradiated patients with resectable rectal carcinoma. Ann Surg 246: 693-701, 2007. 
6. Das P, Lin EH, Bhatia S, Skibber JM, Rodriguez-Bigas MA Feig BW, Chang GJ, Hoff PM,Eng C, Wolff RA, et al: Preoperative chemoradiotherapy with capecitabine versus protracted infusion 5-fluorouracil for rectal cancer: A matched-pair analysis. Int J Radiat Oncol Biol Phys 66: 1378-1383, 2006.

7. Yeo SG, Kim DY, Kim TH, Chang HJ, Oh JH, Park W, Choi DH, Nam H, Kim JS, Cho MJ, et al: Pathologic complete response of primary tumor following preoperative chemoradiotherapy for locally advanced rectal cancer: Long-term outcomes and prognostic significance of pathologic nodal status (KROG 09-01). Ann Surg 252: 998-1004, 2010.

8. Park IJ, You YN, Agarwal A, Skibber JM, Rodriguez-Bigas MA, Eng C, Feig BW, Das P, Krishnan S, Crane CH, et al: Neoadjuvant treatment response as an early response indicator for patients with rectal cancer. J Clin Oncol 30: 1770-1776, 2012.

9. Fokas E, Liersch T, Fietkau R, Hohenberger W, Beissbarth T, Hess C, Becker H, Ghadimi M, Mrak K, Merkel S, et al: Tumor regression grading after preoperative chemoradiotherapy for locally advanced rectal carcinoma revisited: Updated results of the CAO/ARO/AIO-94 trial. J Clin Oncol 32: 1554-1562, 2014.

10. Huebner M, Wolff BG, Smyrk TC, Aakre J and Larson DW: Partial pathologic response and nodal status as most significant prognostic factors for advanced rectal cancer treated with preoperative chemoradiotherapy. World J Surg 36: 675-683, 2012.

11. Zhu J, Gu W, Lian P, Sheng W, Cai G, Shi D, Cai S and Zhang Z: A phase II trial of neoadjuvant IMRT-based chemoradiotherapy followed by one cycle of capecitabine for stage II/III rectal adenocarcinoma. Radiat Oncol 8: 130, 2013.

12. Martin ST, Heneghan HM and Winter DC: Systematic review and meta-analysis of outcomes following pathological complete response to neoadjuvant chemoradiotherapy for rectal cancer. $\mathrm{Br}$ J Surg 99: 918-928, 2012

13. Maas M, Nelemans PJ, Valentini V, Das P, Rödel C, Kuo LJ, Calvo FA, García-Aguilar J, Glynne-Jones R, Haustermans K, et al: Long-term outcome in patients with a pathological complete response after chemoradiation for rectal cancer: A pooled analysis of individual patient data. Lancet Oncol 11: 835-844, 2010

14. Maas M, Beets-Tan RG, Lambregts DM, Lammering G, Nelemans PJ, Engelen SM, van Dam RM, Jansen RL, Sosef M, Leijtens JW, et al: Wait-and-see policy for clinical complete responders after chemoradiation for rectal cancer. J Clin Oncol 29: 4633-4640, 2011.

15. Roh MS, Colangelo LH, O'Connell MJ, Yothers G, Deutsch M, Allegra CJ, Kahlenberg MS, Baez-Diaz L, Ursiny CS, Petrelli NJ, et al: Preoperative multimodality therapy improves disease-free survival in patients with carcinoma of the rectum: NSABP R-03. J Clin Oncol 27: 5124-5130, 2009.

16. Lee CK, Song CW, Rhee JG, Foy JA and Levitt SH: Clinical experience using $8 \mathrm{MHz}$ radiofrequency capacitive hyperthermia in combination with radiotherapy: Results of a phase I/II study. Int J Radiat Oncol Biol Phys 32: 733-745, 1995.

17. Wiersma J, van Wieringen $\mathrm{N}$, Crezee $\mathrm{H}$ and van Dijk JD Delineation of potential hot spots for hyperthermia treatment planning optimisation. Int J Hyperthermia 23: 287-301, 2007.

18. Shoji H, Motegi M, Osawa K, Okonogi N, Okazaki A, Andou Y, Asao T, Kuwano H, Takahashi T and Ogoshi K: Output-limiting symptoms induced by radiofrequency hyperthermia. Are they predictable? Int J Hyperthermia 32: 199-203, 2016.

19. Engstrom PF, Arnoletti JP, Benson AB III, Chen YJ, Choti MA, Cooper HS, Covey A, Dilawari RA, Early DS, Enzinger PC, et al; National Comprehensive Cancer Network: NCCN Clinical Practice Guidelines in Oncology: Rectal cancer. J Natl Compr Canc Netw 7: 838-881, 2009.

20. Japanese Society for Cancer of the Colon and Rectum: Japanese Classification of Colon Carcinoma. 8th edition. Kanehara, Tokyo, 2013.

21. Shoji H, Motegi M, Osawa K, Okonogi N, Okazaki A, Andou Y, Asao T, Kuwano H, Takahashi T and Ogoshi K: A novel strategy of radiofrequency hyperthermia (neothermia) in combination with preoperative chemoradiotherapy for the treatment of advanced rectal cancer: A pilot study. Cancer Med 4: 834-843, 2015.

22. Shoji H, Motegi M, Osawa K, Okonogi N, Okazaki A, Andou Y, Asao T, Kuwano H, Takahashi T and Ogoshi K: Does standardization of radiofrequency hyperthermia benefit patients with malignancies? Ann Cancer Res Ther 22: 28-35, 2014.

23. Shoji H, Motegi M, Osawa K, Okonogi N, Okazaki A, Andou Y, Asao T, Kuwano H, Takahashi T and Ogoshi K: Radiofrequency thermal treatment with chemoradiotherapy for advanced rectal cancer. Oncol Rep 35: 2569-2575, 2016.
24. Therasse P, Arbuck SG, Eisenhauer EA, Wanders J, Kaplan RS, Rubinstein L, Verweij J, Van Glabbeke M, van Oosterom AT, Christian MC, et al: New guidelines to evaluate the response to treatment in solid tumors. European Organization for Research and Treatment of Cancer, National Cancer Institute of the United States, National Cancer Institute of Canada. J Natl Cancer Inst 92: 205-216, 2000.

25. US National Cancer Institute, Cancer Therapy Evaluation Program: Common Terminology Criteria for Adverse Events (CTCAE). http://ctep.cancer.gov/protocolDevelopment/electronic_applications/ctc.htm\#ctc_40. Accessed Feb 16, 2016.

26. Lawrence TS, Davis MA, Tang HY and Maybaum J: Fluorodeoxyuridine-mediated cytotoxicity and radiosensitization require S phase progression. Int J Radiat Biol 70: 273-280, 1996.

27. Chen AY, Chou R, Shih SJ, Lau D and Gandara D: Enhancement of radiotherapy with DNA topoisomerase I-targeted drugs. Crit Rev Oncol Hematol 50: 111-119, 2004.

28. Gmeiner WH, Willingham MC, Bourland JD, Hatcher HC, Smith TL, D'Agostino RB Jr and Blackstock W: F10 inhibits growth of PC3 xenografts and enhances the effects of radiation therapy. J Clin Oncol Res 2: 1028, 2014.

29. O'Connell MJ, Colangelo LH, Beart RW, Petrelli NJ, Allegra CJ, Sharif S, Pitot HC, Shields AF, Landry JC, Ryan DP, et al: Capecitabine and oxaliplatin in the preoperative multimodality treatment of rectal cancer: Surgical end points from National Surgical Adjuvant Breast and Bowel Project trial R-04. J Clin Oncol 32: 1927-1934, 2014.

30. Allegra CJ, Yothers G, O'Connell MJ, Beart RW, Wozniak TF, Pitot HC, Shields AF, Landry JC, Ryan DP, Arora A, et al: Neoadjuvant 5-FU or capecitabine plus radiation with or without oxaliplatin in rectal cancer patients: A Phase III randomized clinical trial. J Natl Cancer Inst 107: djv248, 2015.

31. Craven I, Crellin A, Cooper R, Melcher A, Byrne P and Sebag-Montefiore D: Preoperative radiotherapy combined with 5 days per week capecitabine chemotherapy in locally advanced rectal cancer. Br J Cancer 97: 1333-1337, 2007.

32. Gérard JP, Azria D, Gourgou-Bourgade S, Martel-Lafay I, Hennequin C, Etienne PL, Vendrely V, François E, de La Roche G, Bouché O, et al: Clinical outcome of the ACCORD 12/0405 PRODIGE 2 randomized trial in rectal cancer. J Clin Oncol 30: 4558-4565, 2012.

33. De Ridder M, Tournel K, Van Nieuwenhove Y, Engels B, Hoorens A, Everaert H, Op de Beeck B, Vinh-Hung V, De Grève J, Delvaux G, et al: Phase II study of preoperative helical tomotherapy for rectal cancer. Int J Radiat Oncol Biol Phys 70: 728-734, 2008 .

34. Huang MY, Chen CF, Huang CM, Tsai HL, Yeh YS, Ma CJ, Wu CH, Lu CY, Chai CY, Huang CJ, et al: Helical tomotherapy combined with capecitabine in the preoperative treatment of locally advanced rectal cancer. Biomed Res Int 2014: 352083, 2014.

35. Hernando-Requejo O, López M, Cubillo A, Rodriguez A, Ciervide R, Valero J, Sánchez E, Garcia-Aranda M, Rodriguez J, Potdevin G, et al: Complete pathological responses in locally advanced rectal cancer after preoperative IMRT and integrated-boost chemoradiation. Strahlenther Onkol 190: 515-520, 2014.

36. Lu JY, Xiao Y, Qiu HZ, Wu B, Lin GL, Xu L, Zhang GN and $\mathrm{Hu} \mathrm{K}$ : Clinical outcome of neoadjuvant chemoradiation therapy with oxaliplatin and capecitabine or 5-fluorouracil for locally advanced rectal cancer. J Surg Oncol 108: 213-219, 2013.

37. Rau B, Wust P, Hohenberger P, Löffel J, Hünerbein M, Below C, Gellermann J, Speidel A, Vogl T, Riess H, et al: Preoperative hyperthermia combined with radiochemotherapy in locally advanced rectal cancer: A phase II clinical trial. Ann Surg 227: 380-389, 1998.

38. Petrovich Z, Langholz B, Gibbs FA, Sapozink MD, Kapp DS, Stewart RJ, Emami B, Oleson J, Senzer N, Slater J, et al: Regional hyperthermia for advanced tumors: A clinical study of 353 patients. Int J Radiat Oncol Biol Phys 16: 601-607, 1989.

39. Vasanthan A, Mitsumori M, Park JH, Zhi-Fan Z, Yu-Bin Z, Oliynychenko P, Tatsuzaki H, Tanaka Y and Hiraoka M: Regional hyperthermia combined with radiotherapy for uterine cervical cancers: A multi-institutional prospective randomized trial of the international atomic energy agency. Int J Radiat Oncol Biol Phys 61: 145-153, 2005.

40. Mitsumori M, Zeng ZF, Oliynychenko P, Park JH, Choi IB, Tatsuzaki H, Tanaka Y and Hiraoka M: Regional hyperthermia combined with radiotherapy for locally advanced non-small cell lung cancers: A multi-institutional prospective randomized trial of the International Atomic Energy Agency. Int J Clin Oncol 12: 192-198, 2007. 
41. Issels RD, Lindner LH, Verweij J, Wust P, Reichardt P, Schem BC, Abdel-Rahman S, Daugaard S, Salat C, Wendtner CM, et al; European Organisation for Research and Treatment of Cancer Soft Tissue and Bone Sarcoma Group (EORTC-STBSG); European Society for Hyperthermic Oncology (ESHO): Neo-adjuvant chemotherapy alone or with regional hyperthermia for localised high-risk soft-tissue sarcoma: A randomised phase 3 multicentre study. Lancet Oncol 11: 561-570, 2010.

42. Schroeder C, Gani C, Lamprecht U, von Weyhern $\mathrm{CH}$, Weinmann M, Bamberg M and Berger B: Pathological complete response and sphincter-sparing surgery after neoadjuvant radiochemotherapy with regional hyperthermia for locally advanced rectal cancer compared with radiochemotherapy alone. Int J Hyperthermia 28: 707-714, 2012.

43. Maluta S, Romano M, Dall'oglio S, Genna M, Oliani C, Pioli F, Gabbani M, Marciai N and Palazzi M: Regional hyperthermia added to intensified preoperative chemo-radiation in locally advanced adenocarcinoma of middle and lower rectum. Int J Hyperthermia 26: 108-117, 2010.
44. Powathil GG, Adamson DJ and Chaplain MA: Towards predicting the response of a solid tumour to chemotherapy and radiotherapy treatments: Clinical insights from a computational model. PLOS Comput Biol 9: e1003120, 2013.

45. Holck S, Nielsen HJ,Pedersen N and Larsson LI: Phospho-ERK1/2 levels in cancer cell nuclei predict responsiveness to radiochemotherapy of rectal adenocarcinoma. Oncotarget 6: 34321-34328, 2015.

46. Ebara T, Kaira K, Saito J, Shioya M, Asao T, Takahashi T, Sakurai H, Kanai Y, Kuwano H and Nakano T: L-type amino-acid transporter 1 expression predicts the response to preoperative hyperthermo-chemoradiotherapy for advanced rectal cancer. Anticancer Res 30: 4223-4227, 2010. 